\title{
LA CERÁMICA PROVINCIAL INCA COMO PRODUCTO Y COMO EXPRESIÓN DE ESTATUS EN LA POBLACIÓN MITMAQUNA DE Pueblo Viejo-Pucará
}

\author{
Mayra Carmen Castillo \\ https://orcid.org/0000-0002-7308-8520 \\ Escuela de Posgrado, Pontificia Universidad Católica del Perú \\ mayra.carmen@pucp.pe \\ Krzysztof Makowski Hanula \\ https://orcid.org/0000-0002-1523-1624 \\ Departamento de Humanidades, Pontificia Universidad Católica del Perú \\ kmakows@pucp.edu.pe
}

\begin{abstract}
Resumen
Continuando la línea de investigaciones iniciada hace quince años por los integrantes del Programa Arqueológico Escuela de Campo "Valle de Pachacamac", los autores del presente artículo discuten los resultados del análisis de cerámica que corresponden a imitaciones de estilos imperiales inca que han sido seleccionados entre varios estilos en uso durante el Horizonte Tardio en el valle bajo de Lurín. La muestra proviene de pisos y de contextos excavados en dos residencias palaciegas del asentamiento Pueblo Viejo-Pucará, a $15 \mathrm{~km}$ de Pachacamac, fundado por los mitmaquna procedentes de Huarochirí por iniciativa de la administración imperial inca. Los resultados de análisis de pastas y acabados por medio de microscopia digital fueron confrontados con los estudios previos sobre la procedencia de las fuentes de arcilla, que implicaron el análisis LA-TOF-ICP-MS y el estudio de la variedad de alfares.
\end{abstract}

Este enfoque permite revisar, de manera crítica, dos supuestos ampliamente difundidos en las investigaciones sobre la relación entre el estilo inca y las tradiciones locales en el contexto de debate sobre las identidades cultural, étnica y politica del productor y del usuario: 1) El hipotético control que ejerce el Estado Inca sobre los ceramistas, que se expresaría en la imposición de cánones morfo-estilisticos y tecnológicos cuzqueños a los alfareros locales y 2) La supuesta relación directa entre la identidad étnica y las preferencias estilisticas del usuario local de cerámica, verbigracia el estilo Ychsma o Puerto Viejo. La validez de ninguno de estos supuestos pudo ser confirmada en la producción de la cerámica Inca provincial a cargo de alfareros locales y probables mitmaquna norteños; asimismo en su uso, se refleja un complejo proceso de construcción de identidades nuevas en el contexto cosmopolita del imperio, no sin que algunos aspectos de la identidad de origen se hayan racionalizado, afirmado y materializado.

Palabras clave: Cerámica inca provincial, valle de Lurín, estatus, identidad cultural, étnica y politica del usuario, análisis de pastas con microscopía digital, LA-TOF-ICP-MS.

\section{Abstract}

INCA PROVINCIAL POTTERY AS A PRODUCT AND EXPRESSION OF STATUS OF THE MITMAQUNA SETTLEMENT OF PUEBLO VIEJO-PUCARÁ

Continuing with the line of research initiated fifteen years ago by the members of the Archaeological Program - Field School "Valle de Pachacamac", the authors of this article discuss the results of the analysis of ceramics that correspond to imitations of Inca imperial styles that have been selected among several styles in use during the Late Horizon in the lower valley of Lurin. The sample comes from floors and contexts excavated in two palace residences of the settlement 
Pueblo Viejo-Pucará, $15 \mathrm{~km}$ from Pachacamac, founded by the mitmaqunas from Huarochiri on the initiative of the Inca imperial administration. The results of analysis of pastes and finishes by means of digital microscopy were compared with previous studies on the origin of the clay sources, which involved the analysis LA-TOF-ICP-MS and the study of the ware's variety.

This approach makes it possible to critically review two widely disseminated research assumptions about the relationship between the Inca style and local traditions in the context of debate about the cultural, ethnic and political identities of the producer and user: 1) The hypothetical control exercised by the Inca State over ceramists, which would be expressed in the imposition of morpho-stylistic and technological Cuzco canons on local potters and 2) The supposed direct relationship between ethnic identity and the stylistic preferences of the local ceramic user, e.g. the Ychsma or Puerto Viejo style. The validity of none of these assumptions could be confirmed in the production of provincial Inca ceramics by local potters and the probable northern mitmaquna; likewise, their use reflects a complex process of constructing new identities in the cosmopolitan context of the empire, not without some aspects of the identity of origin having been rationalized, affirmed and materialized.

Keywords: Provincial Inca ceramics, Lurin valley, status, cultural, ethnic and political identity of the user, analysis of pastes with digital microscopy, LA-TOF-ICP-MS.

\section{Introducción}

El presente aporte se enmarca en el proyecto de investigaciones arqueométricas iniciado hace 15 años por los integrantes del Programa Arqueológico Valle de Pachacamac, quiénes se han propuesto reconstruir la red de producción y distribución de cerámica en la Costa Central del Perú mediante el estudio convencional de pastas, formas, acabados, la aplicación de microscopía digital, la búsqueda de fuentes de arcilla entre los valles del Chillón y Chilca, así como el análisis LA-TOF-ICP-MS de pastas y arcillas (Makowski et al. 2008, 2011, 2013, 2015, 2018). A continuación, presentamos los resultados del análisis arqueométrico realizado por la coautora, de 1531 fragmentos correspondientes a imitaciones de estilos cuzqueños. Dichos fragmentos forman parte de una muestra de 15,494 fragmentos de cerámica hallada durante las excavaciones dirigidas por el coautor, en dos residencias de elite en Pueblo Viejo-Pucará, respectivamente en los sectores II y IV de este asentamiento (Figs. 1 y 2).

A juzgar por las fuentes históricas, por el tipo de arquitectura y por sus entierros, los Caringa - quienes construyeron Pueblo Viejo-Pucará-, fueron desplazados desde las alturas de Huarochirí siguiendo el mandato de la administración inca y formando uno de los tres o cuatro ayllus asentados en el valle bajo de Lurín durante el Horizonte Tardío (Makowski 2002; Eeckhout 2009; Espinoza 2014). Su asentamiento principal arriba mencionado fue desocupado poco antes de las reducciones toledanas. La arquitectura residencial, tanto la común como la de élite, se distribuye en cuatro aglomeraciones distanciadas, dos en la parte elevada en las crestas de los cerros y dos en el fondo de las quebradas. En cada una de las dos mitades, la de abajo y la de arriba, se construye una estructura de élite de carácter palaciego, a juzgar por la presencia de ambientes destinados no solo para fines residenciales, sino también preparados para ceremonias religiosas multitudinarias, así como cocinas, patios de reuniones, amplios depósitos y áreas de producción bajo techo. Los habitantes de Pueblo Viejo-Pucará han tenido una posición política privilegiada, que se infiere por el acceso a las imitaciones de la cerámica imperial, a los morteros, artefactos de metal e importantes cantidades de valvas enteras de Spondylus princeps hallados en entierros. Igual de relevante en este sentido es la presencia del ushnu incorporado en la traza de la residencia del curaca principal que domina visualmente las dos plazas en el frontis (Makowski et al. 2005; Makowski y Ruggles 2011). 


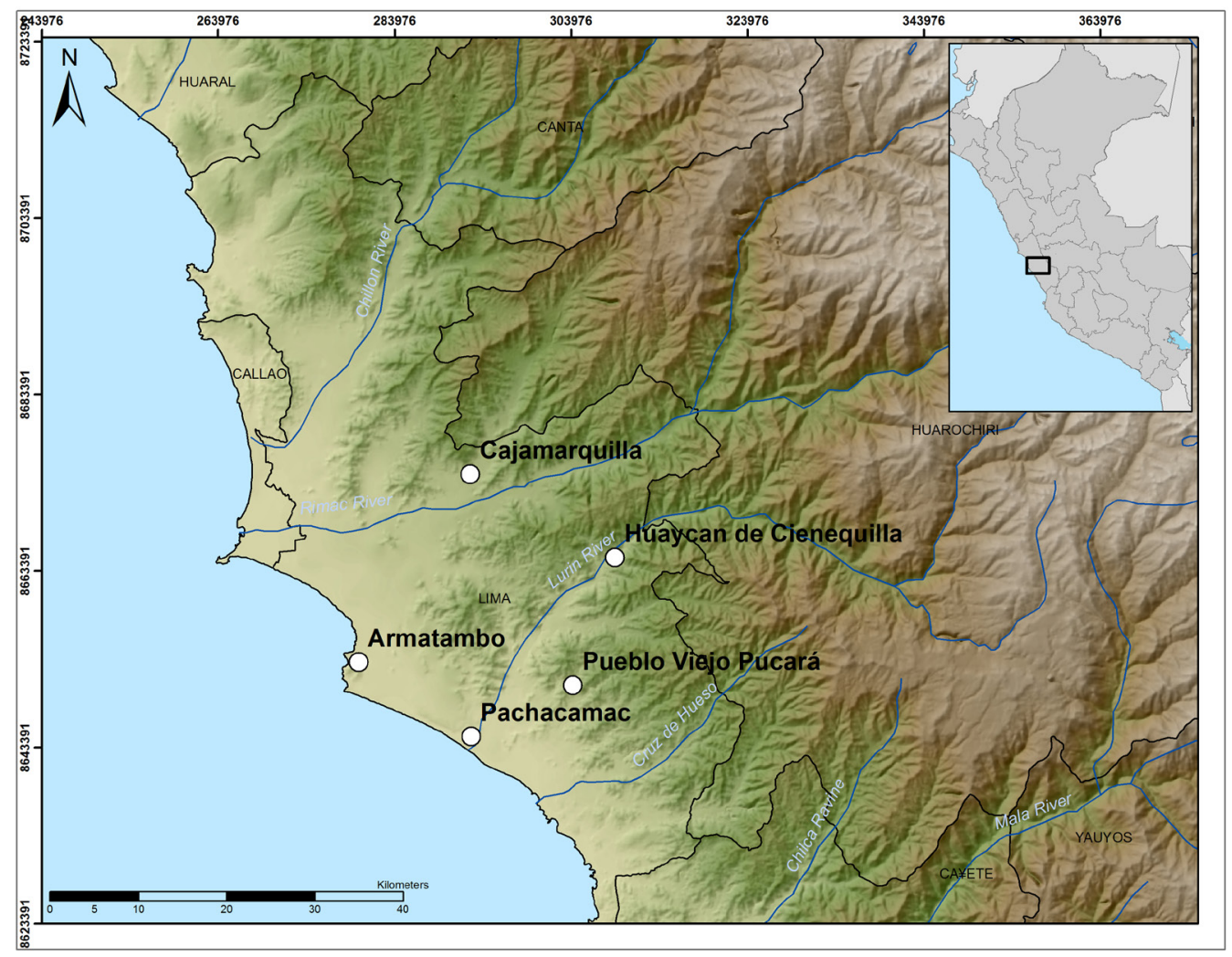

Figura 1. Ubicación de Pueblo Viejo Pucará en el valle de Lurín (G. Oré, en: Makowski et al. 2015).

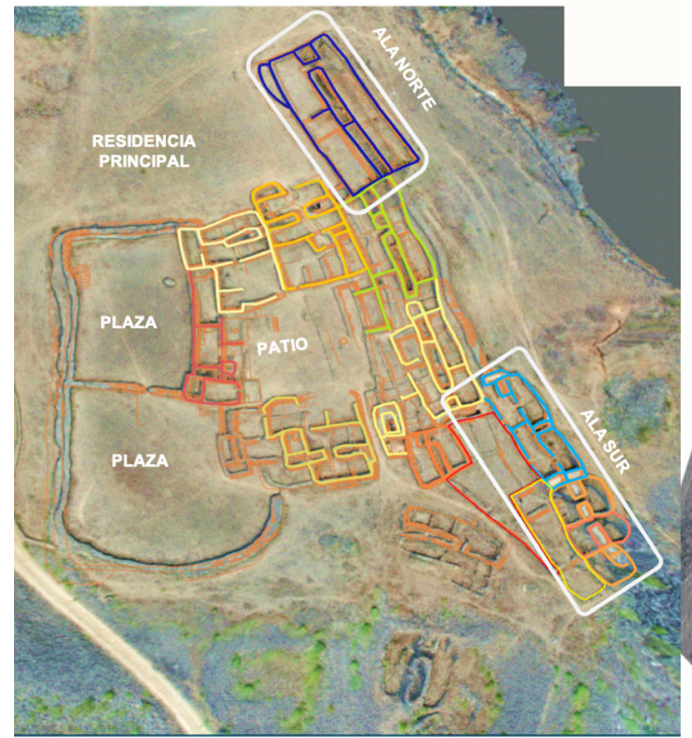

- $-\ldots-\ldots$ - $-{ }_{20} \mathrm{~m} \quad$ Sector II, Arquitectura Cerámica inca

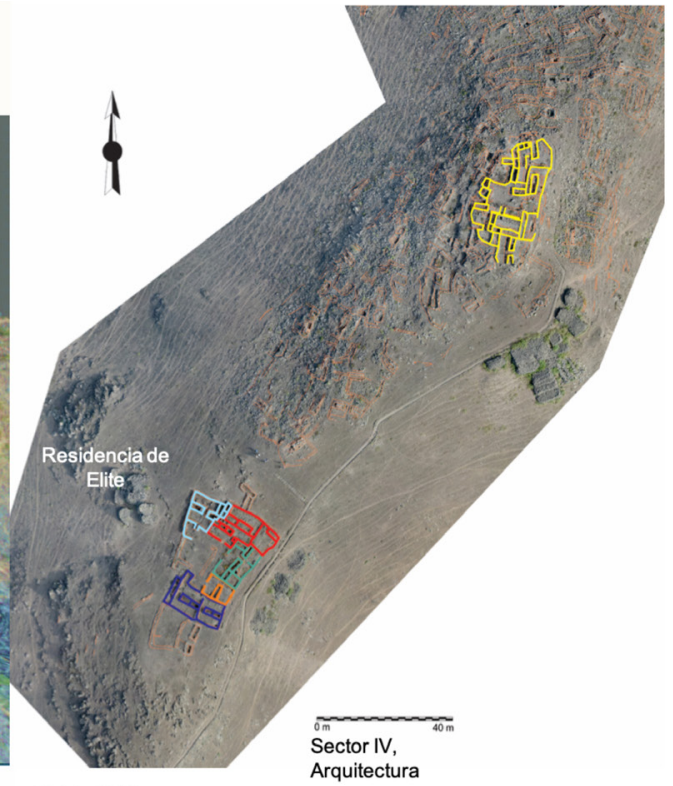

Cerámica inca

Figura 2. Asentamiento de los mitmaquna de Huarochirí en Pueblo Viejo-Pucará: Sectores II y IV (M. Carmen). 


\section{Objetivos y enfoques}

El material cerámico inca, sometido al análisis en este estudio, procede de dos residencias palaciegas, la mayor, correspondiente probablemente a la residencia del curaca principal, ubicada en la parte baja en el sector II y la menor, que se localiza en la parte de arriba, en el sector IV, que podría ser asignada a la segunda persona en el mando (Rostworowski 1972, 1999, 2002; Espinoza 2014). En primera instancia, esta comparación de las dos muestras halladas respectivamente en cada uno de los palacios, una con la otra y ambas con la cerámica de los demás sectores, tuvo por objetivo captar las eventuales diferencias de acceso a la cerámica provincial inca entre los habitantes y usuarios de ambos palacios y por este medio evaluar el papel de la cerámica decorada en la construcción de la identidad política y del estatus de los aliados de los Incas. No obstante, ha habido también otras metas, a saber:

1. Evaluar la incidencia de la aplicación de microscopía digital sobre la clasificación macroscópica de pastas, además de comprobar la eficacia de una nueva modalidad de registro digital de cerámica,

2. Afinar la clasificación de las pastas mediante análisis de microscopía digital y relacionar nuestros resultados vinculados a la producción de cerámica en estilos catalogados como inca provincial con los ya obtenidos sobre grupos químicos y procedencia de arcillas realizados con LA-ICP-MS.

3. Identificar a los productores de la cerámica inca desde la perspectiva tecnológica, por medio del análisis del estilo interno (tecnología de confección y acabado) de artefactos cerámicos.

En la literatura del tema se suele asignar a todos los habitantes de los tres valles de la Costa Central, Lurín, Rímac y Chillón, la misma identidad étnica, la Ychsma (Bazán 1990, 1992; Díaz 2008; Eeckhout 2004a,b; Vallejo 2004, 2008, 2009), la que se expresaría en la producción y el uso de la cerámica llana y decorada, doméstica y ceremonial del mismo nombre (Feltham y Eeckhout 2004; Díaz 2008) y la preferencia por ciertas formas de arquitectura pública como las pirámides con rampa (Eeckhout 1995, 1999a,b, 2003; Díaz 2008;). Muchos investigadores esperaban que la mayoría de las expresiones materiales de esta supuesta identidad desaparezcan del registro cuando este territorio fuera incorporado al Tahuantinsuyu, supuestamente de manera pacífica.

El supuesto no se ha comprobado a la luz de las investigaciones recientes. Los dos estilos cerámicos locales, el Ychsma y el Lurín Marrón, siguen predominando cuantitativamente en las muestras registradas en los niveles del Horizonte Tardío y la influencia de la cerámica cuzqueña se limita a pocas variables de cierta recurrencia como por ejemplo, nuevos tipo de inclusiones en pasta naranja, engobe guinda, las aplicaciones de borde en forma de batracios, el borde biselado «de media flecha», la decoración en forma de serpiente en relieve, formas de ollas con asas horizontales (Feltham e Eeckhout 2004; Makowski y Vega Centeno 2004). Uno de los estilos mencionados -Ychsma-, se producía de arcillas recurrentes en el valle de Rímac, donde según toda probabilidad se situaban también los talleres, mientras que el otro - Lurín Marrón (Makowski y Oré 2013; Makowski et al. 2015) — fue de confección local. En este segundo caso los alfareros hacían uso de fuentes de arcillas situadas en el valle bajo y medio de Lurín. Los repertorios de formas recurrentes en ambos estilos son muy similares y de hecho equivalentes en uso, isocrésticos, a decir de Sackett (1990). Las proporciones de recurrencia de fragmentos de recipientes en cada estilo en los contextos domésticos excavados en el valle de Lurín varían entre 20\% y $40 \%$ de la totalidad de las muestras analizadas. En Pueblo Viejo-Pucará los fragmentos en estilo Lurín Marrón superan estadísticamente al Ychsma (v.g. Makowski y Vega Centeno 2004), a diferencia de los demás asentamientos excavados en el valle, incluyendo a Pachacamac. En cuanto al otro supuesto indicador material de la identidad Ychsma, a saber, los edificios denominados pirámides con rampa (PCR), estos se siguen construyendo durante el Horizonte Tardío (Eeckhout 2010a, b; Svendsen 2011). 
Dado que en la totalidad de los edificios de este tipo se ha encontrado exclusivamente la cerámica Ychsma Tardío, por lo general asociada a las imitaciones del estilo Inca, Makowski (2016 a, b 2017) considera posible que la difusión de las estructuras de este tipo en la Costa Central se deba a la iniciativa de la administración imperial y guarde estrecha relación con la transformación de un centro ceremonial local en el gran santuario-oráculo del culto imperial dedicado al dios Pachacamac. Las pirámides con rampa eran destinadas para la reunión de los fieles en fechas festivas y servían entre otros como lugares del almacenamiento de impuestos.

Al margen de este debate es menester observar que el fundamento teórico en el que se sustenta la definición de la identidad étnica de habitantes de la costa central, como pueblo Ychsma —originalmente el nombre del río Lurín (Cerrón Palomino 2000) — ha sido sometido a una profunda y justificada crítica a fines del siglo XX y en la primera década del XXI (Díaz-Andreu 1996; Jones 1996; Emberling 1997; Renfrew 1996; Shaun 1996; ver también Makowski 2009, 2010a, inter alia). El concepto de la cultura arqueológica que en el supuesto compartido por generaciones de investigadores correspondía a espacios y periodos saturados de objetos y construcciones «formalmente o estilísticamente diagnósticas», y servía para construir narrativas sobre contactos, migraciones y conquistas, ordenadas en la secuencia del «tiempo tipológico» (Fabián 1983: 23), resultó corresponder a un símil de la cultura del estado-nación decimonónico. Dicho concepto se ha forjado en el calor del debate sobre los orígenes de la civilización occidental en la que Kossinna y Childe contaban entre los principales protagonistas (Jones 1996: 64, 65, 78, note 3). El concepto de la cultura arqueológica fue asimismo ideado, casi inventado (Fardon 1987: 176), a la imagen de la cultura material de la época industrial: estilos uniformes de productos fabricados en serie y de construcciones estandarizadas cubrían espacios nacionales. Los sistemas de intercambio del sistema mundo, aún incipientes, no lograban superar fronteras políticas, y estas seguían fáciles de percibir y registrar por medio de la variabilidad de la cultura material ( v.g. caso de armas de fuego en Francia y Alemania analizado por Sackett 1990). El uso del torno rápido en el Mediterráneo desde el inicio de la Edad de Bronce y la producción masificada de manufacturas helenístico-romana (v.g. terra sigilata) reforzaban la convicción de generaciones de estudiosos, que también en las épocas preindustriales, existieron espacios saturados de manera uniforme por el mismo repertorio de tipos de productos, que además guardaban estrechos niveles de similitud en cuanto a las características estilísticas.

Los críticos de la arqueología historicista del siglo XX invitan a dejar de lado el tradicional enfoque de la etnicidad en la arqueología pre- y proto-histórica, y en cambio sugieren adoptar en los estudios de este tema el paradigma de Barth (1969). Para Barth (1969:19), la identidad de los grupos étnicos no se desprende del listado de similitudes y diferencias establecido por el investigador sino de «las categorías de adscripción e identificación que los actores sociales se atribuyen ellos mismos». Se trata de un subjetivo we-feeling que puede ser abordado solo de la perspectiva emic, en lugar de etic (Renfrew 1996: 130). La identidad, vista desde esta perspectiva, es un fenómeno complejo de múltiples facetas y dinámicas. Las identidades étnicas, lingüísticas, religiosas y políticas se conservan o abandonan, se negocian y de hecho suelen acumularse, en particular en el contexto cosmopolita de un sistema-mundo como aquel generado por la formación del Tawantinsuyu. La relación entre las identidades y la cultura material no es nunca directa y simple. Es probable que, en el caso de sociedades andinas del Horizonte Tardío, consideradas frecuentemente urbanas en la literatura, pero cuyo modo de vida, es rural (Makowski 2016b), las idiosincrasias se afirmen e incluso exacerben en el contexto de desplazamientos forzados oponiendo a los vecinos de asentamientos cercanos. Dichas identidades no tienen por qué coincidir siempre con los límites de provincias imperiales, huamanis, y/o de sus subdivisiones administrativas, hunus, ni expresarse de preferencia en las formas y acabados de cerámica doméstica.

Los aspectos perceptibles de la identidad son asimismo siempre dinámicos cuando están vistos desde la perspectiva del tiempo mediano y largo a pesar del peso de la tradición, del habitus 
(Moreno 2015; Van Dijk 2006). Creemos posible detectar, en el caso de los habitantes de Pueblo Viejo-Pucará que buscan construir y legitimar sus identidades bajo el dominio de la administración inca, la expresión material de por lo menos dos procesos de direccionalidad opuesta:

a. Aquellos aspectos y agentes que mantienen la identidad y sirven para autoidentificarse y ser identificados; por ejemplo, los mitmaqunas procedentes de la sierra de Huarochirí, quienes recrean las mismas condiciones de modo de vida en la organización espacial de su asentamiento y mantienen vigentes sus hábitos ancestrales en cuanto a las formas de enterramiento y siguen usando técnicas ancestrales, por ejemplo, en las actividades pastoriles o cuando construyen las anunas, sistemas para captar agua de neblina y almacenarla en el subsuelo. Asimismo, los caringas permanecieron fieles a la organización espacial muy particular de sus espacios de vivienda y a sus técnicas de mampostería y construcción.

b. Aquellas circunstancias en donde la identidad se deconstruye y reconstruye en la medida de que aparezcan nuevos condicionamientos y retos; por ejemplo, al ser trasladados al valle bajo de Lurín, los pobladores adoptan nuevas estrategias económicas y articulan los espacios públicos de su asentamiento de acuerdo a los requerimientos de la administración imperial inca. Se construyen las plazas y el ushnu, implementándose la rígida distribución de áreas de vivienda en mitades y parcialidades. Por otro lado, sus curacas tienen que encontrarse en el nuevo papel de los representantes de la administración inca. Asimismo, los advenedizos están confrontados con sus vecinos y potenciales enemigos costeńos, los ychsma de la margen derecha del valle a los que probablemente están vigilando. Para afirmar sus derechos a las nuevas tierras, los caringas trasladan sus huacas a un nuevo lugar y parecen ofrecer culto al pico más alto de la zona (Makowski y Lizárraga 2011; Makowski y Ruggles 2011).

La producción y los usos de la cerámica son un crisol que refleja estos y otros procesos. Los resultados de nuestra investigación ponen en tela juicio tanto el modelo de la relación directa entre la identidad étnica y el uso de un estilo de cerámica (sea Inca, Ychsma, Lurín marrón) como el modelo — no menos difundido que el precedente-, de un estado que controla al detalle la producción e impone desde la capital rígidos cánones formales y decorativos.

Al respecto se esbozan tres escenarios distintos: En uno de ellos la totalidad o parte de la cerámica inca estaría producida por alfareros locales, estos mismos quienes elaboraban a diario las vasijas en estilos Ychsma, Puerto Viejo y Lurín Marrón, incluyendo las formas utilitarias para almacenaje y cocción de alimentos. En el segundo escenario, se trataría de ceramistas con cierto grado de especialización, formados para confeccionar vajilla fina y decorada de servicio en estilos finos, locales y foráneos. En el tercer escenario, y el menos probable. los productores habrían sido preparados para realizar sus actividades en talleres altamente especializados en las imitaciones de la cerámica imperial cuzqueña. Cabrían también otras alternativas resultantes de la combinación de todas o algunas de las alternativas anteriores.

Es así que los pobladores de Pueblo Viejo-Pucará usan en simultáneo vasijas de varios estilos tanto en el ámbito cotidiano como festivo (Makowski et al. 2015) y ninguno de estos estilos se produce en el asentamiento o en su cercanía, a juzgar por la ausencia de evidencias de manufactura y cocción, y la ubicación de probables fuentes de arcilla. La cerámica inca imperial, en su versión provincial de Lurín y Rímac, es por supuesto la más apreciada. El acceso a cerámica fina y otros objetos símbolos de una posición privilegiada en la sociedad y no son exclusivos para los habitantes de ambos palacios. No obstante, cabe observar que los hallazgos de ambos palacios y en particular del principal destacan en varios aspectos en comparación con los demás sectores: por el mayor porcentaje de fragmentos de cerámica inca provincial, y por la presencia de piezas muy finas y elaboradas, y también aquellas que destacan por diseño o acabado innovador (Carmen y Makowski 2018) (Fig. 3). 
1416

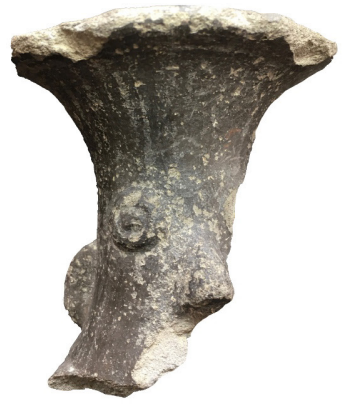

-

724

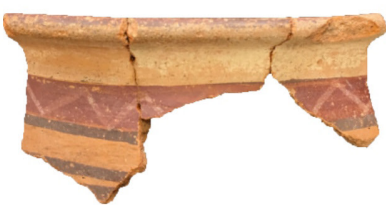

$\square \square$

585

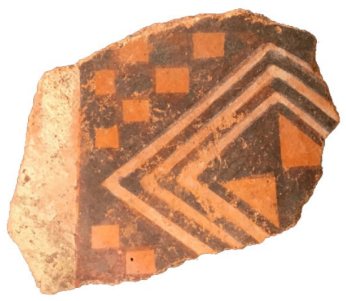

$\square$

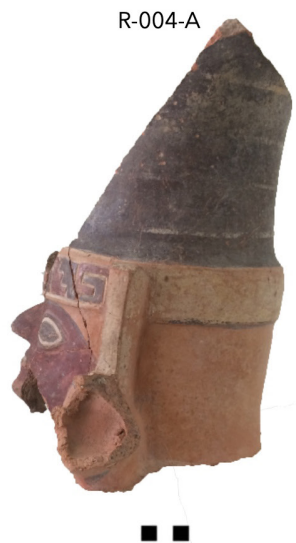

892

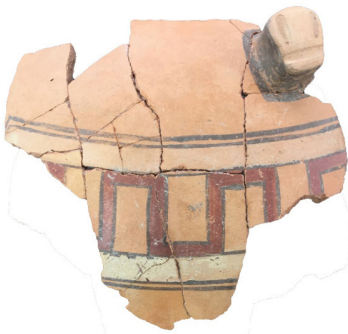

-

1434

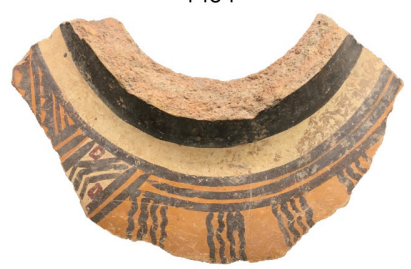

口

1292

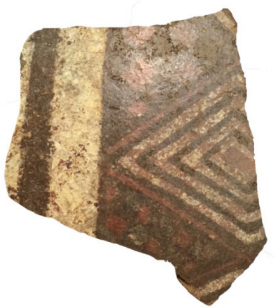

口

R-004-B

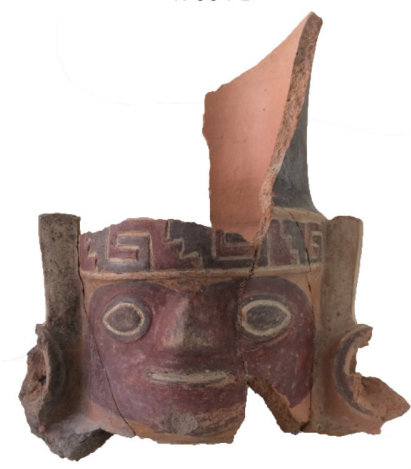

$\square \square$

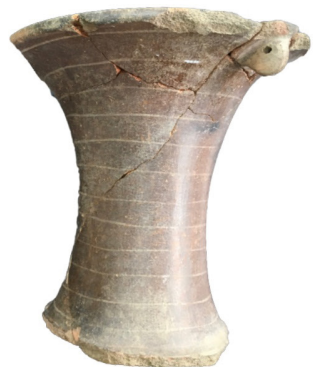

-

724

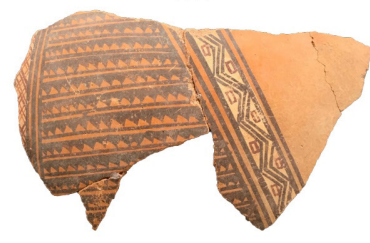

-

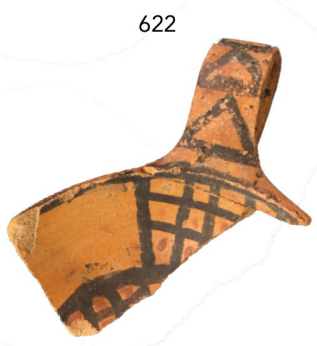

口

621

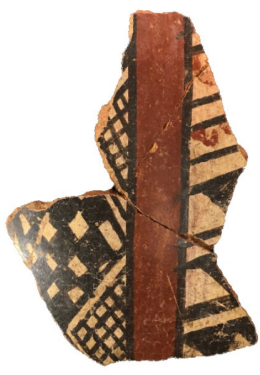

$\square \square$

Figura 3. Muestra de cerámica inca provincial procedente de Pueblo Viejo-Pucará. (M. Carmen). 


\section{Metodología}

En el estudio analítico de la cerámica cuyos resultados presentamos en este artículo se ha tomado en cuenta tanto los aspectos del estilo interno (tecnología de confección y acabado) como del estilo externo (formas, aspectos cromáticos y diseños). En cuanto al primer aspecto se ha hecho uso de la clasificación macroscópica del material cerámico procedente de Pueblo Viejo-Pucará, Pachacamac y Huaycán de Cieneguilla, la que comprende veinte tipos de pasta con sus respectivas variantes, agrupadas en dieciséis alfares (Makowski 2006, 2010b, 2011, 2013, 2015). Se ha encontrado con bastante frecuencia casos de vasijas en estilos diferentes, las que sin embargo fueron producidas de la misma manera en cuanto a la preparación de pasta, eventual selección de temperantes y de procedimientos de construcción de la vasija, así como de tipo de cocción. Por ende, varios alfares resultaron pluriestilísticos. Cada alfar corresponde a una tradición tecnológica, a un taller o grupo de talleres. En concordancia con las clasificaciones establecidas previamente por diferentes investigadores que trabajaron en el valle de Lurín, se ha mantenido la subdivisión en cinco grupos estilísticos de cerámica, confeccionada con pastas originarias de los valles bajos de Lurín y Rímac:

- Inca provincial o Inca Lurín, mayormente imitaciones de Cuzco Polícromo A;

- Lurín Negro, con frecuentes imitaciones de Chimú-Inca;

- Lurín Marrón, llamado también «estilo serrano»;

- Puerto Viejo, a veces considerado una variante decorada de Ychsma, a pesar de su recurrencia al sur del Lurín, entre Chilca y Cañete.

- Ychsma, llamado también Lurín Naranja (Makowski et al. 2015).

Cabe recordar que la muestra de más de 50,000 fragmentos diagnósticos, analizados durante los últimos 15 años por generaciones de jóvenes investigadores, quienes emplearon la misma metodología y la misma terminología, llegando a clasificaciones plenamente coincidentes, provienen de tres sitios ubicados en diferentes lugares del valle bajo: Pachacamac, famoso santuario y oráculo (Eeckhout 1999b; Makowski 2016b), Huaycán de Cieneguilla, el asentamiento con arquitectura residencial típica para el valle bajo de Lurín (Álvarez-Calderón 2011), y Pueblo Viejo-Pucará, asentamiento principal de los mitmaquna, conocidos como los caringa de Huarochirí. Las muestras de Pachacamac provienen principalmente de las áreas de tránsito en la calle Norte-Sur y en el vestíbulo de la entrada al Templo del Sol. En todos los sitios mencionados se ha encontrado la mayoría de alfares de la lista, pero en proporciones distintas. Solo Pachacamac destaca por la presencia minoritaria de alfares ausentes en las muestras procedentes de los demás asentamientos, algunos de ellos probablemente importados.

A diferencia de los estudios previos, arriba mencionados, en los que se ha sometido al estudio la totalidad de material, la coautora se ha propuesto investigar a profundidad las muestras de la cerámica inca, incluyendo los estilos asociados como el chimú-inca. En el análisis de formas y diseños se ha servido de variables y taxones propuestos por Rowe (1944), Meyers (1975), Julien (2004) y Bray $(2004,2008)$. De las siete modalidades de composiciones decorativas, según Julien (2004), ha identificado en la muestra analizada la recurrencia de los modos A y B (que corresponden al Cuzco Polícromo A y B de Rowe (1944)). En cuanto a aspectos tecnológicos, los de estilo interno, se ha revisado la clasificación macroscópica de pastas y alfares con microscopía óptica (Druc y Chávez: 2014) (Fig. 4). Esto ha permitido confirmar la validez de la clasificación y asimismo corregir algunos errores. Gracias a ello fue posible sacar provecho de los resultados de análisis arqueométricos de pastas y de muestras de arcilla con LA-ICP-MS (Makowski y Oré 2013; Makowski et al. 2015) y de este modo definir el probable lugar de confección de la cerámica inca de Pueblo Viejo-Pucará.

En la documentación gráfica de cerámica hemos usado una modalidad de registro digital que mantiene vigentes todas las convenciones del dibujo técnico (Bagot 2005) y un alto nivel de precisión, pero asimismo permite un ahorro considerable de tiempo en comparación con el registro convencional a lápiz. Los equipos utilizados fueron un iPad Pro y un Apple pencil, con el 

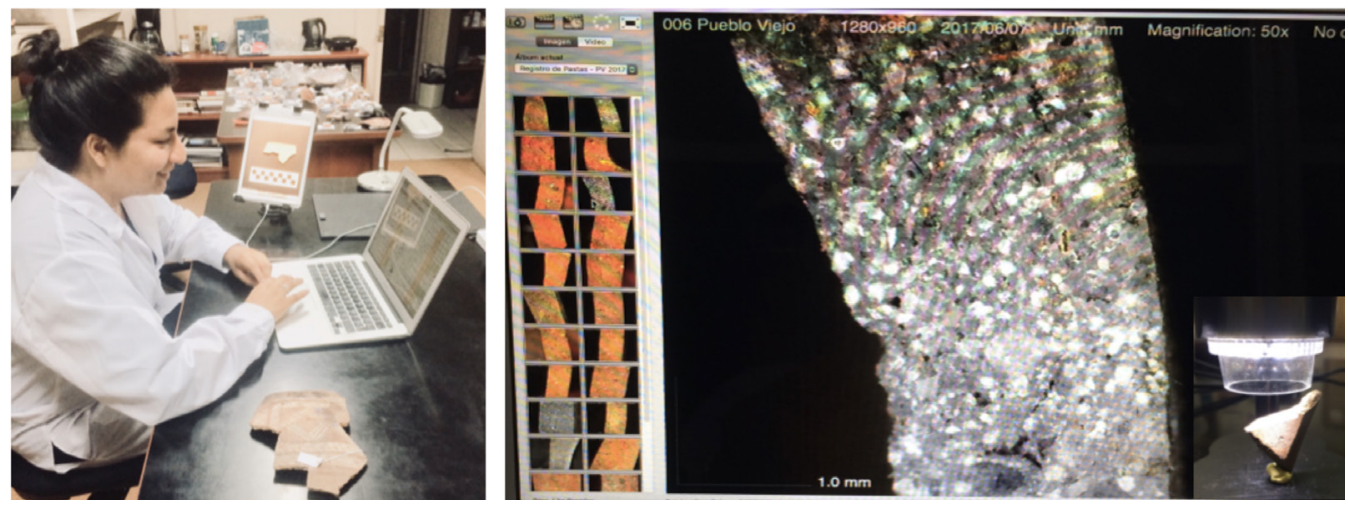

Figura 4. Proceso del registro interno de pastas y análisis arqueométrico de cerámicas inca (M.Carmen).
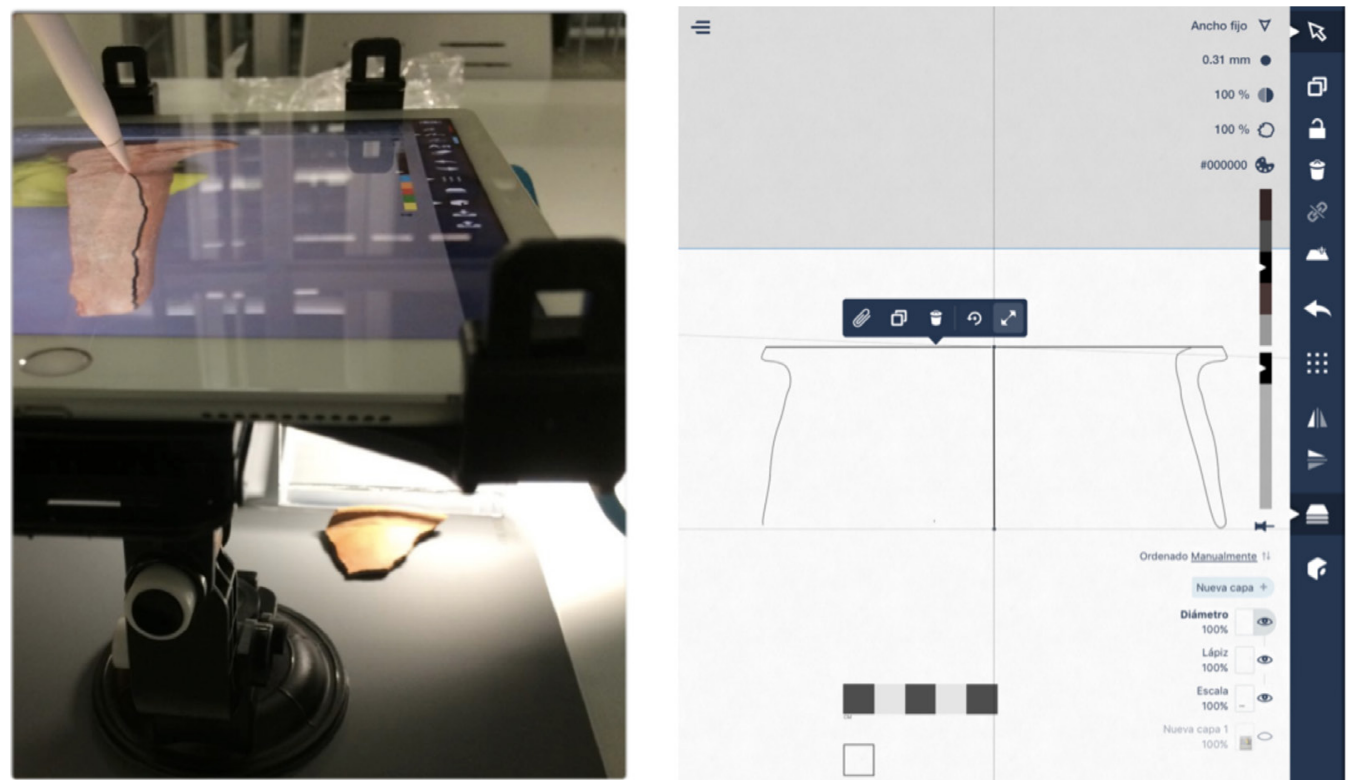

Figura 5. Detalle del registro digital de cerámica aplicado con óptimos resultados en la muestra de cerámica inca de Pueblo Viejo-Pucará (M. Carmen).

que se obtuvo directamente el dibujo técnico vectorizado. La opción Live Photos con estabilización, HDR y modo ráfaga permitió captar el acabado de superficie además del registro de forma, decoración, y microfotografías de la pasta, logradas gracias a su avanzada estabilización óptica de imagen. (Carmen e.p. 2018) (Fig. 5).

Este registro digital complementa las múltiples herramientas de medición con el registro de una foto nivelada y escalada en un soporte estable que se traslada a una aplicación para su dibujo con lápiz. La precisión alcanzada por el Apple pencil no presenta mayor diferencia con el dibujo convencional en papel —salvo una mejor precisión—- por lo que no hay un traslado de datos reiterado y con ello algún margen de error posible. Las convenciones del dibujo técnico se mantuvieron en la medida que tomamos el diámetro y la inclinación como insumo para orientar el dibujo y capturar la imagen. Asimismo, por recomendación de Daniel Gianonni (comunicación personal) - experto y reconocido fotógrafo de patrimonio_- se implementó la corrección de distorsión óptica, siendo plenamente válidada la foto del registro bidimensional con escala de objetos. 


\section{Resultados}

Nuestros estudios de microscopía digital forman parte de una cadena de investigaciones arqueométricas de largo alcance que busca comprender la cadena operativa en la producción cerámica inca provincial del valle de Lurín. Bajo este preámbulo, se considera necesario hacer una breve introducción sobre los estudios previos realizados por el proyecto para entender las interpretaciones derivadas en esta investigación.

\subsection{Estudios previos al estudio de microscopía digital}

La investigación arqueométrica llevada a cabo por el Programa Arqueológico Valle de Pachacamac, se ha estructurado en varias etapas a lo largo de los últimos quince años. En la primera etapa se ha realizado el análisis macroscópico de material cerámico procedente de los contextos excavados en Pueblo Viejo-Pucará (Makowski 2002; Makowski y Vega Centeno 2004; Makowski et al. 2005; Makowski y Lizárraga 2011; Makowski y Ruggles 2011), Pachacamac (Makowski 2015; Oré 2008; Bringas 2015) y Huaycán de Cieneguilla (Álvarez-Calderón 2011). En la segunda etapa llegó el turno de las muestras procedentes de la parte de las excavaciones en la parte media y alta del valle de Lurín, dirigidas por Hernández, Chase y Milan (Makowski et al. 2015; Chase 2016).

Gracias a los resultados de la comparación entre las pastas del valle bajo y las de la parte alta se ha podido descartar el origen exclusivamente serrano del estilo Lurín Marrón. Posteriormente se ha logrado demostrar por medio de análisis LA-TOF-ICP-MS que solo las arcillas de la parte media fueron aprovechadas por ambos grupos de alfareros, los que abastecían de sus productos la sierra y también a los que distribuían sus vasijas en la costa. En la tercera etapa de investigaciones se han realizado prospecciones geológicas en los valles de Chilca, Chillón, Rímac y Lurín con el fin de ubicar fuentes potenciales de arcillan (Makowski y Oré 2013). En la cuarta etapa se ha sometido al análisis LA-TOF-ICP-MS 640 muestras de cerámica y 163 muestras de arcilla.

Los resultados fueron procesados con aplicación de rutinas estadísticas MURR y mediante análisis discriminante Mahalanobis (Makowski et al. 2006; Makowski et al. 2008; Makowski et al. 2015). De esta manera se logró asignar las muestras a tres grupos químicos mediante la proyección de Cesio (Cs) y Rubidio (Rb), tal como se muestra en la Tabla 1 (Fig. 6).

\subsection{Resultados del análisis de microscopía digital}

Hay que destacar que el análisis composicional ha respaldado plenamente los taxones establecidos a partir del estudio macroscópico previo. Por ejemplo, $91.2 \%$ de las muestras de pasta G2 se asocian con el Grupo 3, mientras que 87.5\% de las muestras de la pasta E2 corresponden al Grupo 1.

La investigación, cuyos resultados acabamos de resumir, puso en claro que los pobladores de Pueblo Viejo-Pucará usaban en simultáneo vasijas de varios estilos tanto en el ámbito cotidiano como festivo (Fig. 7). Las vasijas fueron producidas por varios grupos de alfareros que seguían tradiciones tecnológicas distintas y cuyos talleres se encontraban lejos del asentamiento. El trueque y eventualmente la distribución por medio de la red de administración imperial aseguraba el abastecimiento.

No se ha comprobado la existencia de alguna relación entre el origen étnico de los usuarios y las preferencias por un estilo determinado de cerámica. Ha habido un consenso entre los investigadores que la cerámica de pasta naranja fina, supuestamente de manufactura local en los valles bajos de Lurín y Rímac, fue producida y usada en exclusividad por los integrantes de la sociedad Ychsma (Bazán 1992; Feltham y Eeckhout 2004; Vallejo 2004, 2009). A la luz de los resultados de nuestras investigaciones, los alfareros que la producen usan de preferencia arcillas procedentes de valle de Rímac (Grupo químico 2) y los recipientes son de amplia distribución incluyendo a 


\begin{tabular}{|c|c|c|}
\hline Grupo químico & Estilo & Zonas probables de fuentes de arcilla \\
\hline $\begin{array}{l}\text { Grupo } 1 \\
\text { (uni-estilístico) }\end{array}$ & \multirow[t]{2}{*}{$\begin{array}{l}\text { Características químicas propias } \\
\text { a fragmentos de vasijas en estilo } \\
\text { Lurín Marrón Serrano de tipo do- } \\
\text { méstico. }\end{array}$} & \multirow{2}{*}{$\begin{array}{l}\text { Se identificaron dos zonas probables de ex- } \\
\text { tracción en el valle de Lurín: la primera ubi- } \\
\text { cada en la margen derecha del valle bajo, en } \\
\text { la zona de Lúcumo cerca de Pueblo Viejo } \\
\text { y la segunda en la misma margen, en valle } \\
\text { medio-alto cerca de Sisicaya. }\end{array}$} \\
\hline Alfar: 5 & & \\
\hline $\begin{array}{l}\text { Grupo } 2 \\
\text { (multi-estilístico) }\end{array}$ & \multirow{2}{*}{$\begin{array}{l}\text { Características químicas en propias } \\
\text { a fragmentos de vasija mayormente } \\
\text { en estilo Ychsma y de forma mino- } \\
\text { ritaria en estilos Inca Lurín (Cuzco } \\
\text { Polícromo), Chimú - Inca y Puerto } \\
\text { Viejo. }\end{array}$} & \multirow[t]{2}{*}{$\begin{array}{l}\text { Se identificaron zonas probables de extrac- } \\
\text { ción en el valle bajo del Rímac, cerca de } \\
\text { Cajamarquilla en Huachipa. }\end{array}$} \\
\hline $\begin{array}{l}\text { Alfar: } 1,3,9,10 \\
12,13\end{array}$ & & \\
\hline $\begin{array}{l}\text { Grupo } 3 \\
\text { (multi-estilístico) }\end{array}$ & \multirow{2}{*}{$\begin{array}{l}\text { Características químicas propias a } \\
\text { fragmentos estilo Inca de línea fina, } \\
\text { elaborada para el consumo cere- } \\
\text { monial de alimentos y bebidas, así } \\
\text { como botellas escultóricas Ychsma. }\end{array}$} & \multirow{2}{*}{$\begin{array}{l}\text { Se identificó un área probable de extrac- } \\
\text { ción de recursos cerca al centro administra- } \\
\text { tivo Armatambo, ubicado en el valle bajo } \\
\text { del Rímac. }\end{array}$} \\
\hline $\begin{array}{l}\text { Alfar: } 1,2,4,6 \\
7,8,11,14,16\end{array}$ & & \\
\hline
\end{tabular}

Tabla 1. Cuadro elaborado con base en los resultados obtenidos en la relación de grupos químicos vs. estilos y alfares (Makowski et al. 2015, la traducción es nuestra).

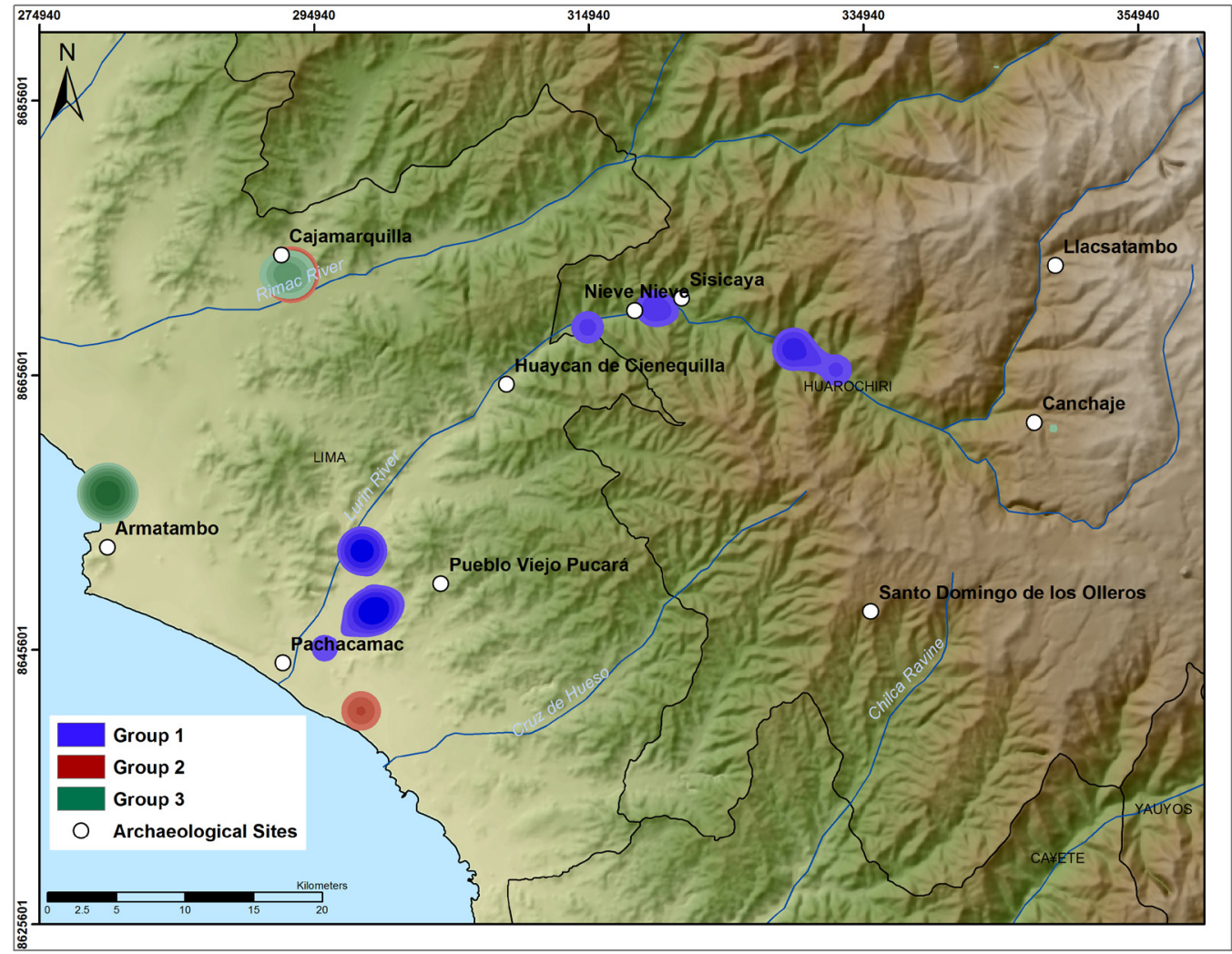

Figura 6. Grupos químicos (G. Oré, en: Makowski et al. 2015). 


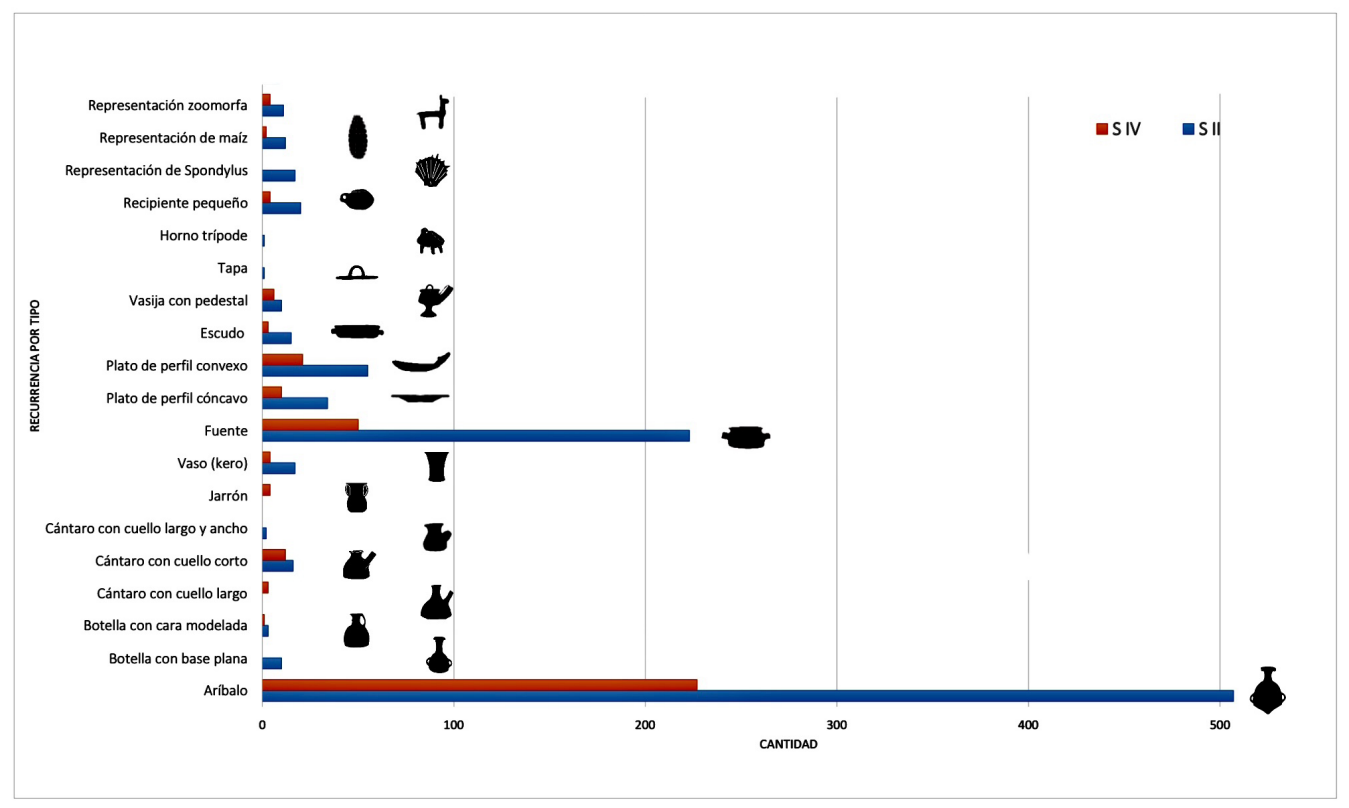

Figura 7. Recurrencia de los tipos de la cerámica inca por sector en Pueblo Viejo-Pucará (M. Carmen).

los mitmaquna de la sierra de Huarochirí, asentados en Pueblo Viejo-Pucará. La cerámica de pasta marrón gruesa, que se suponía típicamente serrana por el color de pasta y engobe y ciertas preferencias formales (Guerrero 2004; Makowski y Vega Centeno 2004), fue elaborada por los ceramistas costeńos que se abastecían de arcillas en el valle bajo y medio de Lurín (Grupo químico 1). No se puede afirmar sobre la base de estos resultados que la identidad étnica de los pobladores de Lurín (Ychsma) se expresa en las preferencias por el estilo Lurín Marrón y la del valle de Rímac en el estilo Ychsma, dado que los fragmentos de ambos estilos están presentes en todos los sitios excavados y fechados para los periodos tardíos en ambas cuencas. Tampoco es posible asignar el uso de los demás estilos a un grupo poblacional o a un asentamiento en particular. No parece por ende que la elección de un estilo de cerámica utilitaria, decorada o no, haya sido un vehículo importante de la identidad étnica de los usuarios en el Periodo Horizonte Tardío en la Costa Central. La distribución espacial de artefactos en estilos locales, Ychsma, Lurín Marrón y Puerto Viejo, parece demarcar, en primera instancia, las redes de intercambio de vasijas y eventualmente a los movimientos de alfareros (Ramón 2013).

El caso de las imitaciones de estilos exóticos de mucho prestigio es por supuesto diferente. Cabe resaltar, sin embargo, que los análisis composicionales no dejaron lugar a dudas, que casi toda la cerámica provincial inca fue hecha de las mismas pastas y según los mismos procedimientos tecnológicos, salvo el acabado, que las vasijas Lurín Marrón o Ychsma.

La cerámica inca imperial, en su versión provincial de Lurín y Rímac fue, por supuesto, la más apreciada y la menos recurrente. No obstante, su uso ha sido generalizado y no se restringía al área de las dos estructuras palaciegas. Los estilos locales predominan estadísticamente en todas las muestras de los cinco sectores excavados que corresponden a la totalidad del área construida del asentamiento, sumando por lo general entre $90 \%$ y $98 \%$ de la totalidad de fragmentos registrados en cada unidad.

De las variantes estilísticas cuzqueñas de Rowe (1944) y Julien (2004), un porcentaje relativamente alto, el $9.88 \%$ de 15,431 fragmentos analizados por la coautora corresponden al estilo Inca Provincial. La mayor parte de fragmentos proviene de la residencia palaciega mayor, sumando 
1100 fragmentos, el $72 \%$ de la totalidad de la muestra. No obstante, el porcentaje de fragmentos de imitaciones de cerámica imperial, respecto a la totalidad de tiestos registrados, es similar en ambos casos: $9.86 \%$ en el palacio mayor, y $9.94 \%$ en el palacio menor.

Tal como era de esperar, los fragmentos de gran calidad y diseńos que fielmente reproducen los modelos cuzqueńos tienen mayor recurrencia en la muestra procedente del palacio mayor. El acceso a artefactos en estilo inca, en sus variantes provincial y local, no solo pudo haber sido condicionado por el rango y el estatus del individuo, sino también desprenderse de la posición privilegiada del grupo, linaje o ayllu. Hemos visto que el análisis de la cadena operativa en los aspectos accesibles por medio de estudio arqueométrico permite contrastar negativamente, para el caso de Lurín, el supuesto difundido de que la producción de la cerámica imperial estuvo centralizada y bajo estricto control del estado. Los resultados de nuestras investigaciones apuntan que la producción fue descentralizada y estuvo a cargo de alfareros locales que usaban arcillas procedentes de Lurín y Rímac. En la muestra sometida al análisis de microscopía digital, la mayor parte de vasijas inca estuvieron producidas con cuatro pastas (Tabla 2, Fig. 8).

- Pasta G1: que representa al 87.3\% de la muestra, elaborada con la arcilla procedente del valle del Rímac, base del alfar Ychsma Lurín Naranja que incluye variantes muy finas, de cocción oxidante, textura granular, granulometría fina y distribución mixta y homogénea, proceso de afinamiento de la arcilla, buen nivel de amasado y distribución uniforme de temperantes.

- Pasta E2: que representa al 3.7\% de la muestra, hecha con la arcilla procedente del valle de Lurín, base del alfar Lurín Marrón, cocción reductora con enfriamiento oxidante o engobe naranja, de textura granular, granulometría gruesa controlada media, granos bien distribuidos, compacta, proceso de afinamiento para eliminar facciones gruesas y buen trabajo de amasado para lograr este tipo de compactación y,

- Pastas D y H: que representa al 7.4\% de la muestra, elaborada con la arcilla procedente del valle medio del Rímac y/o bajo de Lurín, base del alfar Lurín Negro. Tienen cocción reductora, textura laminar, ocasionalmente granular con eliminación de facción gruesa y granos bien distribuidos, así como buen amasado de la pasta compacta unimodal.

\begin{tabular}{|c|c|c|c|c|c|c|l|}
\hline Alfar & Pasta & Textura & Distribución & $\begin{array}{c}\text { Porosidad/ } \\
\text { Compactación }\end{array}$ & Color & Inclusiones & Tamaño \\
\hline 4 & D & Laminar & Homogéneo & Semi-poroso & Gris & $\begin{array}{l}\text { Cuarzo lechoso, frag- } \\
\text { mentos de rocas negra } \\
\text { y roca roja opaca }\end{array}$ & $\begin{array}{l}\text { Muy fina, } \\
0.1 \mathrm{a} \\
0.5 \mathrm{~mm}\end{array}$ \\
\hline 4 & $\mathrm{H}$ & Granular & Irregular & Poroso & Gris & $\begin{array}{l}\text { Cuarzo lechoso, frag- } \\
\text { mentos de roca negra } \\
\text { opaca, mica dorada }\end{array}$ & $\begin{array}{l}\text { Mediana, } \\
0.5 \mathrm{a} \\
2 \mathrm{~mm}\end{array}$ \\
\hline 5 & E-2 & Granular & Irregular & Poroso & Marrón & $\begin{array}{l}\text { Cuarzo lechoso, frag- } \\
\text { mentos de roca negra, } \\
\text { mica dorada }\end{array}$ & $\begin{array}{l}\text { Gruesa, } \\
0.5 \mathrm{a} \\
2 \mathrm{~mm}\end{array}$ \\
\hline 6 & G-1 & Granular & Irregular & Poroso & Naranja & $\begin{array}{l}\text { Cuarzo lechoso, frag- } \\
\text { mentos de rocas negra } \\
\text { opaca, beige y roja, } \\
\text { mica dorada }\end{array}$ & $\begin{array}{l}\text { Fina, } 0.5 \\
\text { a } 1.5 \mathrm{~mm}\end{array}$ \\
\hline
\end{tabular}

Tabla 2. Alfares y caracterización de pastas cerámicas incas identificadas en Pueblo Viejo-Pucará.

Por otro lado, tenemos un grupo minoritario de pastas que no han sido identificadas con anterioridad en Lurín. Creemos que se trataría de vasijas importadas de diferentes lugares distantes (Fig. 9). Cabe mencionar que en el material analizado hemos encontrado un amplio espectro 


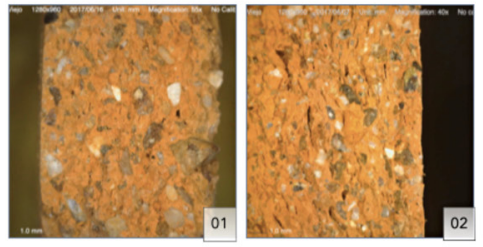

Pasta gruesa, composición y granulometría mixtas

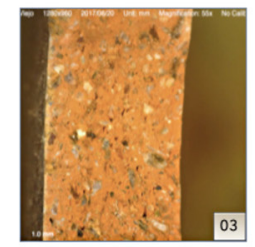

Pasta mediana y granulometría controlada

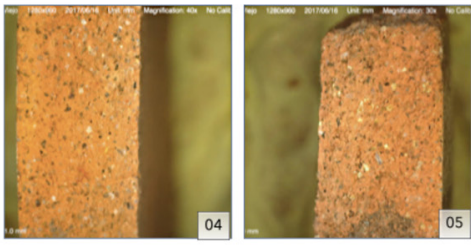

Pasta fina, distribución equilibrada de inclusiones

PASTA 01 - Variantes - Similar a Pasta G1 CERÁMICA YCHSMA NARANJA

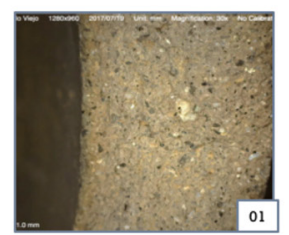

Pasta mediana, unimodal

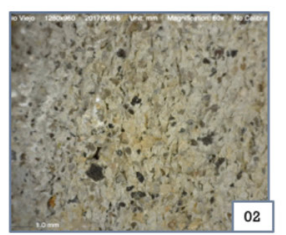

Pasta mediana, con cavidades

PASTE 02 - SIMILAR A PASTA D Y H CERÁMICA LURÍN NEGRO

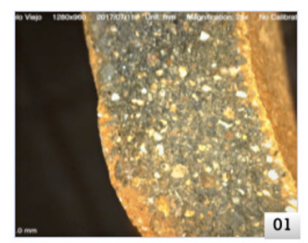

Pasta mediana, compacta, distribución uniforme

PASTE 03 - SIMILAR A PASTA E2 CERÁMICA LURÍN MARRÓN

Figura 8. Tipos de pastas con variantes identificadas en la cerámica inca de la muestra (M. Carmen).

de actitudes de alfareros respecto a las normas y características de la cerámica imperial Cuzco Polícromo. Hay imitaciones fieles de alfareros maestros, otros menos logrados y también hay innovaciones más o menos ingeniosas, como las que fueron encontradas en el palacio mayor del Sector II, probable residencia del curaca principal.

A su vez, en cuanto al acabado, el engobe es una característica que distingue la cerámica inca registrada. Dos técnicas son posibles de identificar mediante el uso de microscopía óptica. La primera consiste en colocar engobe del mismo color de la pasta o de color crema, rojo, morado o negro, mientras que la segunda aparenta serlo, por lo que se la denomina como un falso engobe (Fig. 10). En este segundo caso el alfarero opta por pasar por la superficie de la cerámica un paño húmedo, permitiendo así uniformizarla para que el agua contenida en esa capa se sobreexponga y luzca como si se hubiese agregado (Druc, comunicación personal, 2017). Dentro del corpus de cerámica identificado, la mayoría presenta falso engobe. El uso de engobe real, crema, blanco, rojo, morado, naranja y negro, es menos recurrente.

La recurrencia de hallazgos de cerámica inca provincial en todos los contextos domésticos excavados, incluso los más modestos, no solo en los dos palacios, pone en relieve que el acceso a las vasijas decoradas inspiradas por los estilos cuzqueños, y los de la costa norte, no solo fue un elemento diferenciador para aquellos que tuvieron mayor jerarquía y deseaban ostentarla en la vida pública, sino que su uso también podría ser entendido como una forma de hacer patente la posición privilegiada del grupo, del macroayllu, respecto a la administración del hunu y del huamani. De este modo, el dinamismo en la construcción de la identidad política respecto a la herencia étnica se expresa en el cosmopolitismo de la vajilla cuyo uso no se limita a las residencias de los curacas.

Las imitaciones de los estilos imperiales dentro del corpus de la cerámica exótica, utilizada en particular en los espacios de agasajo y fiesta, no implican el abandono de los estilos ancestrales. Estos últimos siguen vigente en formas utilitarias decoradas y no decoradas, algunas incluso de probable uso ceremonial. Por ejemplo, los cántaros miniatura Lurín Marrón fueron utilizados en las ceremonias del templete de la cima (Makowski y Lizárraga 2011). En este caso, el uso de 

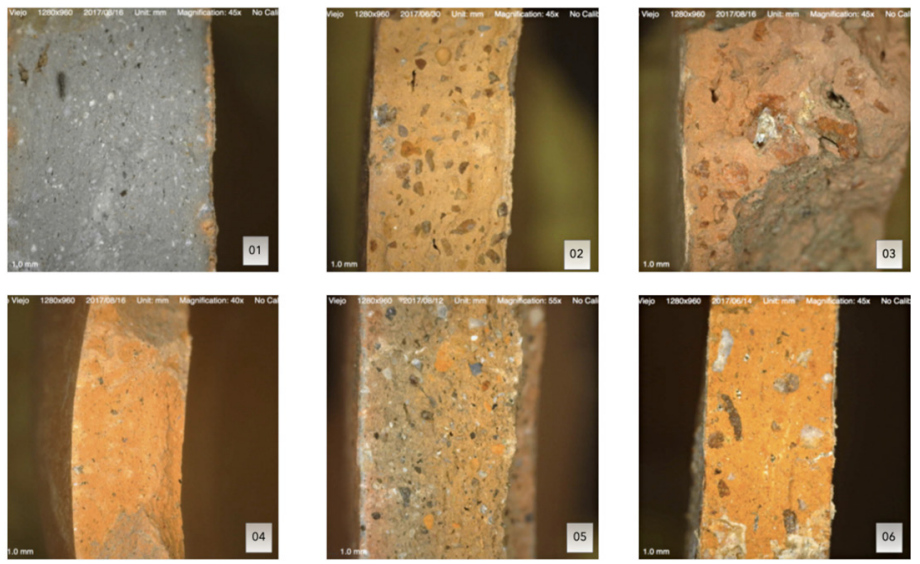

Figura 9. Pastas incas importadas, no identificadas con anterioridad en las pastas de cerámica inca de Pueblo ViejoPucará (M. Carmen).
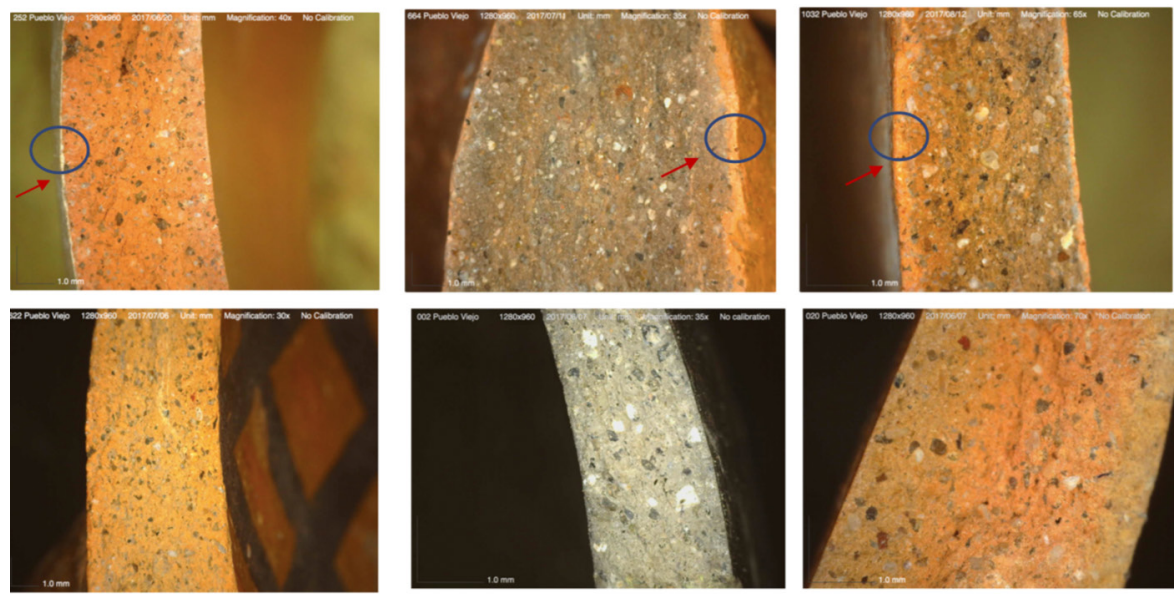

Figura 10. Aplicación de engobes (parte superior) y falso engobe (parte inferior) en pastas cerámicas incas procedentes de Pueblo Viejo-Pucará (M. Carmen).

determinados objetos no refleja cambios drásticos en la identidad de los usuarios como grupo aliado, pero sí es un probable vehículo para establecer distancias de estatus en una sociedad con estilo de vida notablemente igualitario en muchos aspectos.

\section{Conclusiones}

Como se desprende del análisis, cuyos alcances fueron resumidos en este artículo, la cerámica inca procedente de las excavaciones en los palacios del sitio Pueblo Viejo Pucará, la cual fue confeccionada con cuatro pastas: D y H, G1 y E2. La validez de esta clasificación, realizada primero de forma macroscópica por varios investigadores del Programa Arqueológico-Escuela de Campo Valle de Pachacamac, ha sido comprobada con la microscopía digital por la coautora. A juzgar por el repertorio de formas y acabados, las pastas $\mathrm{D}$ y $\mathrm{H}$ correspondían a la misma tradición tecnológica particular, un taller o un grupo de talleres, denominado en nuestra clasificación el alfar 4, y responsable en la mayoría de casos por la producción de vasijas en estilo Lurín Negro, a menudo Chimú-Inca. Los fragmentos asignados a las pastas $\mathrm{D}$ y $\mathrm{H}$, y analizados por medio 
de LA-ICP-MS, pertenecen al mismo grupo químico 3, junto con las muestras de arcilla del valle medio del Rímac y/o bajo de Lurín (Tabla 3).

La pasta G1, característica para el alfar 6, pertenece a este mismo grupo químico 3 y por ende comparte con el alfar anterior las mismas fuentes de arcilla. No obstante, los alfareros que usan la pasta G1 producen mayormente la cerámica en estilo Ychsma Lurín Anaranjado.

La cuarta pasta E2, junto con la E1, fue usada por ceramistas quiénes se servían de fuentes de arcilla locales, del valle de Lurín bajo, conclusión que se desprende del hecho que las muestras de arcilla y los fragmentos sometidos al análisis LA-ICP-MS pertenecen al mismo grupo químico 1. De las pastas E1 y E2 se confeccionaba por lo general la cerámica doméstica Lurín Marrón.

Llama poderosamente atención la ausencia, en la muestra de cerámica inca proveniente de ambos palacios, de los fragmentos de alfares cuyas características químicas los permiten asignar al Grupo químico 2. Se trata de alfares estadísticamente recurrentes en Pachacamac, Huaycán de Cieneguilla o en los demás sectores de Pueblo Viejo (I y III). El 54.7\% de los tiestos cuyas pastas poseen estas características pertenece al estilo Ychsma, con los estilos Puerto Viejo, Inca Costeño y Chimú-Inca representados en menores porcentajes.

A juzgar por el origen de arcillas, los habitantes de los dos palacios se abastecían de vasijas inca producidas potencialmente en el valle de Rímac, en un 94.7\% de la muestra analizada, hecha tanto por los alfareros que producían recipientes cerámicos en estilo Ychsma, como los que estaban diestros en la confección de vasijas pulidas cocidas en ambiente reductor, incluyendo buenas imitaciones chimú-inca. Tan solo el 3.7\% de vasijas en estilo inca fueron hechas por ceramistas diestros en la confección de vasijas Lurín Marrón producidas de arcillas de origen local cuyas fuentes estaban situadas en la relativa cercanía de Pueblo Viejo-Pucará. En el presente estado de investigación, resulta probable que los habitantes de otras áreas residenciales (Sectores I, III, IV-1 y V) tuvieron acceso a la cerámica inca producida de arcillas del grupo químico 2 por los alfareros que a diario confeccionaban la cerámica utilitaria en estilo Ychsma. Esta hipótesis tendrá que ser contrastada en el futuro.

En el material analizado hemos encontrado un amplio espectro de actitudes de alfareros respecto a las normas y características de la cerámica imperial Cuzco Polícromo. Hay imitaciones fieles de alfareros maestros, otros menos logrados y también hay innovaciones más o menos ingeniosas. Las vasijas hechas en talleres de mayor fidelidad y pericia fueron encontradas en el palacio mayor del Sector II. En cambio, los habitantes del palacio menor estuvieron usando vasijas producidas por los alfareros que gozaron de mayor libertad en cuanto a las innovaciones.

No hemos encontrado en nuestro análisis argumentos a favor de un modelo centralizado para la producción de las imitaciones de vasijas en estilo imperial a cargo de especialistas dedicados exclusivamente a esta tarea. La confección de la cerámica Ychsma, Puerto Viejo e Inca estuvo a cargo de alfareros que se servían de las fuentes de arcilla del valle bajo del Rímac. Es importante subrayar que las vasijas Inca-Imperial fueron producidas aparentemente con las mismas recetas tecnológicas que la cerámica local, Ychsma Naranja y Lurín Marrón.

Es posible, aunque aún no comprobado, que alfareros foráneos estuvieron produciendo buena parte de vasijas Lurín Negro en estilos de inspiración de la costa norte y otros de tipo local. Hasta el presente no hemos podido comprobar de manera fehaciente que la presencia de la administración inca haya implicado algún cambio claro en el procedimiento de la preparación de arcilla, como por ejemplo cierta estandarización de temperantes o el uso preferencial de ciertos minerales para este fin. Los productores de la cerámica Lurín Marrón, hecha de las arcillas procedentes de Lurín mismo, la que recibe fuerte influencia formal de la sierra, raras veces se encargaba de imitar el estilo imperial, quizás debido a la menor calidad de sus fuentes de arcilla. Hay que repensar por ende el papel del imperio en la producción y distribución de estos bienes de prestigio. Tal parece que ni la imposición ni el control estrecho estuvieron tan necesarios como se suele pensar. Por cierto, faltan aún varias etapas en nuestro intento de reconstruir las cadenas operativas y entre ellos, el análisis 


\begin{tabular}{|c|c|c|}
\hline $\begin{array}{l}\text { Grupo } \\
\text { químico }\end{array}$ & Estilo y pasta & $\begin{array}{l}\text { Zonas probables de } \\
\text { fuentes de arcilla }\end{array}$ \\
\hline Grupo 1 & $\begin{array}{l}\text { Características químicas, propias a la cerámica en estilo } \\
\text { inca, confeccionada con la pasta E2, usada también en la } \\
\text { producción de la vajilla en estilo Lurín Marrón (Serrano). }\end{array}$ & \multirow{2}{*}{$\begin{array}{l}\text { Valle de Lurín: } \\
\text { Margen derecha, valle } \\
\text { bajo, en la zona de } \\
\text { Lúcumo cerca de Pueblo } \\
\text { Viejo. } \\
\text { Margen derecha, valle } \\
\text { medio-alto cerca de } \\
\text { Sisicaya. }\end{array}$} \\
\hline $\begin{array}{l}\text { Alfar: } 5 \\
\text { Pasta: E2 } \\
3.7 \%\end{array}$ & $\begin{array}{l}\text { Cocción reductora con enfriamiento oxidante o engobe } \\
\text { naranja. } \\
\text { Textura granular. } \\
\text { Granulometría gruesa controlada. } \\
\text { Granos bien distribuidos, compacta. Proceso de afina- } \\
\text { miento que elimina facciones gruesas y buen trabajo de } \\
\text { amasado. }\end{array}$ & \\
\hline $\begin{array}{l}\text { Alfar: } 1,3 \text {, } \\
9,10,12,13\end{array}$ & \multicolumn{2}{|c|}{$\begin{array}{l}\text { No se ha registrado en la muestra proveniente de las dos residencias palaciegas frag- } \\
\text { mentos de cerámica inca que se hayan fabricado con alguna pasta asignada a este } \\
\text { grupo, el que comprende en su mayoría a vasijas en estilos Ychsma y Puerto Viejo. } \\
\text { A este mismo grupo } 2 \text { corresponden también muestras de arcilla proveniente de } \\
\text { Cajamarquilla, margen derecha de Rímac, por lo que las fuentes de materia prima se } \\
\text { ubicaban probablemente en esta zona. }\end{array}$} \\
\hline Grupo 3 & $\begin{array}{l}\text { Características químicas propias de la cerámica en estilo } \\
\text { Inca de línea fina, confeccionada con pasta G1, elaborada } \\
\text { para el consumo ceremonial de alimentos y bebidas, así } \\
\text { como botellas escultóricas Ychsma. }\end{array}$ & \\
\hline $\begin{array}{l}\text { Alfar: } 6 \text { y } 4 \\
\text { Pasta: } \\
\text { 6: G1 } \\
\text { 4: D y H }\end{array}$ & $\begin{array}{l}\text { Alfar } 6 \\
\text { Alfar 6: Pasta } \text { G1: que representa al } 87.3 \% \text { de la mues- } \\
\text { tra, elaborada con la arcilla procedente del valle del Rímac, } \\
\text { base del alfar Ychsma Lurín Naranja que incluye variantes } \\
\text { muy finas, de cocción oxidante, textura granular, granulo- } \\
\text { metría fina y distribución mixta y homogénea, proceso de } \\
\text { afinamiento de la arcilla, buen nivel de amasado y distribu- } \\
\text { ción uniforme de temperantes. } \\
\text { Alfar 4: Pastas } D \text { y H: que representa al } 7.4 \% \text { de la mues- } \\
\text { tra, elaborada con la arcilla procedente del valle medio } \\
\text { del Rímac y/o bajo de Lurín, base del alfar Lurín Negro. } \\
\text { Cocción reductora, textura laminar/granular con elimina- } \\
\text { ción de facción gruesa y granos bien distribuidos, así como } \\
\text { buen amasado de la pasta compacta unimodal. }\end{array}$ & $\begin{array}{l}\text { Valle bajo del Rímac: } \\
\text { Cerca al centro adminis- } \\
\text { trativo Armatambo. }\end{array}$ \\
\hline
\end{tabular}

Tabla 3. Cuadro de grupos químicos vs. estilos y alfares inca provincial en los sectores II y IV de Pueblo Viejo-Pucará, elaborado a partir de los resultados de nuestra investigación.

de engobes y de pigmentos en diferentes tipos de la cerámica decorada inspirada por los modelos cuzqueños.

Los resultados obtenidos refuerzan nuestro convencimiento que ninguno de los estilos considerados locales, de la costa y sierra central, verbigracia Ychsma, Lurín Marrón, llamado también Serrano, o Puerto Viejo, puede servir por si solo para determinar el origen y la identidad étnica de los productores o los usuarios. En su estrategia política, los jefes no desaprovecharon oportunidades para manifestar su posición en la jerarquía de poder y su relación privilegiada con el imperio, deconstruyendo así su identidad. 


\section{Agradecimientos}

Extendemos nuestro agradecimiento a la Pontificia Universidad Católica del Perú y a la Asociación UNACEM por el financiamiento otorgado, a los editores, a Isabelle Druc, Jorge Sáez Paz, Luis Cáceres Rey, Cynthia Vargas, Leonardo Zavala y a los colegas del Programa Arqueológico Valle de Pachacamac por los comentarios recibidos en el proceso de análisis y presentación de resultados.

\section{REFERENCIAS}

Álvarez-Calderón, R. (2008). Aproximaciones al uso de los espacios públicos en un asentamiento del Horizonte Tardío: el caso de Huaycán de Cieneguilla en el valle de Lurín, tesis de licenciatura, Departamento de Humanidades, Pontificia Universidad Católica del Perú, Lima.

Bagot, F. (2005). El dibujo arqueológico: La cerámica: normas para la representación de las formas y decoraciones de las vasijas, IFEA, Lima.

Barth, F. (1969). Introduction, en: F. Barth (ed.), Ethnic Groups and Boundaries, 9-38, Little Brown, Boston.

Bazán, F. (1990). Arqueología y etnohistoria de los periodos prehispánicos tardíos de la costa central del Perú, tesis de licenciatura, Universidad Nacional Mayor de San Marco, Lima.

Bazán, F. (1992). Evaluación del término huancho. Los estilos de cerámica de Lima a fines del Horizonte Medio, en: Arqueología de Lima, Crearte, Lima.

Bray, T. (2004). La alfarería imperial inka: Una comparación entre la cerámica estatal del área de Cuzco y la cerámica de las provincias, Chungará 36(2), 365-374.

Bray, T. (2008). The Role of Chicha in Inca State Expansion: A Distributional Study of Inca Aríbalos, en: J. Jennings y B. Bowser (eds.), Drink, Power, and Society in the Andes, 108-132, University Press of Florida, Gainesville. https://doi.org/10.5744/florida/9780813033068.003.0005

Bringas, A. (2015). Cronología de la primera muralla de Pachacamac, tesis de licenciatura, Departamento de Humanidades, Pontificia Universidad Católica del Perú, Lima.

Carmen Castillo, M. (2018). Variantes metodológicas y modalidades de registro en el análisis tecnológico de la cerámica inca provincial de Pueblo Viejo-Pucará, Ciclo de conferencias Mujeres en la Arqueología: pasado, presente y futuro, contribuciones a la praxis arqueológica del Perú. Ponencia presentada en el Museo Nacional de Arqueología, Antropología e Historia del Perú. Lima.

Carmen, M., y K. Makowski (2018). Styles, technology and identities: origins and uses of provincial Inca ceramics in Pueblo Viejo-Pucará, a Huarochiri's mitmaquna settlement in the Lurin Valley, Symposium ¿Are we Inkas? Inkas and local polities Interactions as seen through the Material Culture, ponencia presentada en la 83va reunion annual de la Society for American Archaeology, Washington, D.C.

Cerrón Palomino, R. (2000). «Hurín»: un espejismo léxico opuesto a «Hanan», en: J. Flores Espinosa y R. Varón Gabai (eds.), El hombre y los Andes. Homenaje a Franklin Pease, 219-235, Fondo Editorial de la Pontificia Universidad Católica del Perú, Lima.

Chase, Z., J. (2016). What is a Wak'a? When is a Wak'a, en: Tamara L. Bray (ed.), The archaeology of Wak'as: Explorations the sacred in the pre-Columbian Andes, University Press of Colorado, Boulder.

Díaz, L. (2008). Aproximaciones hacia la problemática del territorio Ychsma, Arqueología y Sociedad 19, 115-127.

Díaz-Andreu, M. (1996). Constructing identity through culture: the past in the forging of Europe, en: P. Graves-Brown, S. Jones y C. Gamble (eds), Cultural identity and archaeology. The Construction of European Communities, 48-61, Routledge, London/New York.

Druc, I. y L. Chavez (2014). Pastas cerámicas en lupa digital: componentes, textura y tecnología, Deep University Press, Blue Mounds.

Eeckout, P. (1995). Pirámide con rampa n 3 de Pachacamac, costa central del Perú. Resultados preliminares de la primera temporada de excavaciones (zona 1 y 2), Bulletin de l'Institut Français d'Études Andines 24(1), 65-106.

Eeckout, P. (1999a). Pirámide con rampa No III, Pachacamac. Nuevos datos, nuevas perspectivas, Bulletin de l'Institut Français d'Études Andines 28(2), 169-214.

Eeckout, P. (1999b). Pachacamac durant l'Intermédiaire Récent. Étude d'un site monumental prehispánique de la Côte centrale du Pérou. BAR International Series, 747, Hadrian Books Ltd., Oxford.

Eeckout, P. (2003). Diseño arquitectónico, patrones de ocupación y formas de poder en Pachacamac, Costa central del Perú, en: Revista Española de Antropología Americana 33, 17-37.

Eeckout, P. (2004a). La sombra de Ychsma. Ensayo introductorio sobre la arqueología de la costa central del Perú en los periodos tardíos, Bulletin de l'Institut Français d'Études Andines 33(3), 403-423. 
Eeckout, P. (2004b). Reyes del sol y señores de la luna. Inkas e Ychsmas en Pachacámac, en: Chungará 36(2), 495-503.

Eeckout, P. (2009). Poder y jerarquías ychsmas en el valle de Lurín, en: Arqueología y Sociedad 19, 223-240.

Eeckout, P. (2010a). Las pirámides con rampa de Pachacamac durante el Horizonte Tardío, en: R. Romero y T. P. Svendsen, eds. Arqueología en el Perú: Nuevos aportes para el estudio de las sociedades andinas prehispánicas, 415-434. Anheb Impresiones, Lima.

Eeckout, P. (2010b). Nuevas evidencias sobre costumbres funerarias en Pachacamac, en: P. Kaulicke, M. Fischer, P. Masson y G. Wolff (eds.), Max Uhle (1856-1944). Evaluaciones de sus investigaciones y obras, 151-164, Fondo Editorial PUCP, Lima.

Emberling, G. (1997). Ethnicity in complex societies: Archaeological perspectives, Journal of Archaeological Research 5, 295-344. https://doi.org/10.1007/BF02229256

Espinoza Soriano, W. (2014). La etnia Ishma (Ychsma, Ichma, ichmay), en: Investigaciones Sociales UNMSM 19(32), 117-159.

Fabian, J. (1983). Time and the Other. How Anthropology Makes its Object. Columbia University Press, New York.

Fardon, R. (1987). «African ethnogenesis»: limits to the comparability of ethnic phenomena, en: L. Holy (ed.), Comparative Anthropology, 168-187, Basil Blackwell, London.

Feltham, J. y P. Eeckout (2004). Hacia una definición del estilo Ychsma: Aportes preliminares sobre la cerámica Ychsma tardía de la pirámide III de Pachacamac, Bulletin de l'Institut Français d'Etudes Andines 33(3), 643-679.

Guerrero, D. (2004). Cronología cerámica y patrones funerarios del valle del Rímac: una aproximación a los períodos tardíos, en: L. F. Villacorta (ed.), Puruchuco y la sociedad de Lima: Un homenaje a Arturo Jiménez Borja, CONCYTEC, Lima.

Jones, S. (1996). Discourses of identity in the interpretation of the past, en P. Graves-Brown, S. Jones y C. Gamble (eds.), Cultural identity and archaeology. The Construction of European Communities, 62-80, Routledge, London/New York.

Julien, C. (2004). Las tumbas de Sacsahuaman y el estilo Cuzco-Inca, Nawpa Pacha 25-27, 1-125.

Makowski, K. (2002). Arquitectura, estilo e identidad en el Horizonte Tardío: el sitio de Pueblo Viejo - Pucará, valle de Lurín, Boletín de Arqueología PUCP 6, 137-170.

Makowski, K. (2006). Proyecto Arqueológico-Taller de Campo «Lomas de Lurin» PATL (antes Tablada de Lurín), Informe de la temporada de trabajo 2005/2006, INC, Lima.

Makowski, K. (2009). Virú-Moche Relations: Technological Identity, Stylistic Preferences, and the Ethnic Identity of Ceramic Manufacturers and Users, en: J.-F. Millaire y M. Morlion (eds.), Gallinazo: an early cultural tradition on the Peruvian North Coast, 17-32, Institute of Archaeology Press/University of California Press, Los Angeles.

Makowski, K. (2010 a). Las relaciones entre Virú y Moche desde la perspectiva del Alto Piura, en: R. Romero Velarde y T. Pavel Svendsen (eds.), Arqueología en el Perú: nuevos aportes para el estudio de las sociedades andinas prehispánicas, 71-104, Anheb Impresiones, Lima.

Makowski, K. (2010 b). Programa Arqueológico-Escuela de Campo «Valle de Pachacamao PATL (antes Tablada de Lurin, Valle de Lurin), Informe de la temporada de trabajo 2008/2009, INC, Lima.

Makowski, K. (2011). Programa Arqueológico-Escuela de Campo «Valle de Pachacamao» PATL (antes Tablada de Lurín, Valle de Lurin), Informe de la temporada de trabajo 2010/2011, Ministerio de Cultura, Lima.

Makowski, K. (2013). Programa Arqueológico-Escuela de Campo «Valle de Pachacamao PATL (antes Tablada de Lurin, Valle de Lurin), Informe de la temporada de trabajo 2011/2012, Ministerio de Cultura, Lima.

Makowski, K. (2015). Programa Arqueológico-Escuela de Campo «Valle de Pachacamao» PATL (antes Tablada de Lurin, Valle de Lurín), Informe de la temporada de trabajo 2013/2014, Ministerio de Cultura, Lima.

Makowski, K. (2016a). Programa Arqueológico-Escuela de Campo «Valle de Pachacamao PATL (antes Tablada de Lurin, Valle de Lurín), Informe de la temporada de trabajo 2015, Ministerio de Cultura, Lima.

Makowski, K. (2016b). Urbanismo andino. Centro ceremonial y ciudad en el Perú prehispánico, Apus Graph Ediciones, Lima.

Makowski, K. (2017). Programa Arqueológico-Escuela de Campo «Valle de Pachacamac» PATL (antes Tablada de Lurin, Valle de Lurin), Informe de la temporada de trabajo 2016, Ministerio de Cultura, Lima.

Makowski, K., M. Córdova, P. Habetler y M. Lizárraga (2005). La plaza y la fiesta: Reflexiones acerca de la función de los patios en la arquitectura pública prehispánica de los periodos tardíos, Boletín de Arqueología PUCP 9 , 297-333.

Makowski, K., I. Ghezzi, D. Guerrero, H. Neff, M. Jimenez, G. Oré y R. Álvarez-Calderón (2008). Pachacamac, Ychsma y los Caringas: Estilos e identidades en el valle de Lurín Inca, en: O. Pinedo y H. Tantaleán (comps.). Arqueología de la costa centro sur peruana, 267-316, Avqi eds., Lima. 
Makowski, K. y M. Lizárraga (2011). El rol de Spondylus princeps en los rituales intracomunitarios de Pueblo ViejoPucará, Estudios del Hombre 29, 333-366.

Makowski, K. y G. Oré (2013). Alfareros de aquí o de allá: identidad estilística y tecnológica en el valle de Pachacamac (costa central peruana, Revista Española de Antropología Americana 43(2), 515-536.

Makowski, K., I. Ghezzi, H. Neff y G. Oré, (2015). Networks of Pottery Production and Exchange in the Late Horizon: Characterization of Pottery Style and Clays on the Central Coast of Peru, en: I. Druc (ed.), Ceramic Analysis in the Andes, 139-155, Deep. University Press, Wisconsin-Madison.

Makowski, K. y C. Ruggles (2011). Watching the sky from the ushnu: the sukanka-like summit temple in Pueblo Viejo-Pucara (Lurin Valley, Peru) en: C. Ruggles (ed.), Archaeostronomy and Ethnoastronomy: Building Bridges between cultures, Proceedings of the 278th Symposium of the International Astronomical Union and l'Oxford IXI' International Symposium of Archeoastronomy, 169-177. Cambridge University Press, Cambridge.

Makowski, K. y M. Vega Centeno (2004). Estilos regionales en la costa central en el Horizonte Tardío. Una aproximación desde el valle del Lurín, Bulletin de l'Institut Françaisd'Etudes Andines 33(3), 681-714. https://doi. org/10.4000/bifea. 5314

Meyers, A. (1975). Algunos problemas en la clasificación del estilo incaico, Pumapunku 8, 7-25.

Moreno, J. (2015). Pensar la ideología y las identidades políticas: aproximaciones teóricas y usos prácticos, Estudios políticos (México) 35, 39-59.

Oré, G. (2008). Aspectos cronológicos y funcionales de la ocupación inca a lo largo de la segunda muralla: Excavaciones en los sectores SE A, SW B Y SW D en Pachacamac, tesis de licenciatura, Departamento de Humanidades, Pontificia Universidad Católica del Perú, Lima.

Ramón, J. G. (2013). Los alfareros golondrinos: productores itinerantes en los Andes, IFEA, Lima.

Renfrew, C. (1996). Prehistory and the identity of Europe, or, don't let's be beastly to the Hungarians, en P. Graves-Brown, S. Jones y C. Gamble (eds.), Cultural identity and archaeology. The Construction of European Communities, 125-137, Routledge, London/New York.

Rostworowski, M. (1972). Breve informe sobre el Señorío de Ychma o Ychima, Arqueología PUC 13, 37-51.

Rostworowski, M. (1999). El Señorio de Pachacamac: el informe de Rodrigo Cantos de Andrade de 1573, IEP/BCRP, Lima.

Rostworowski, M. (2002). Señoríos indígenas de Lima y Canta. [1978], en: Pachacamac. Obras completas II, 189-376, IEP, Lima.

Rowe, J. H. (1944). An introduction to the archaeology of Cuzco, The Museum, Cambridge, Mass.

Sackett, J. R. (1990). Style and ethnicity in archaeology: The case for isochrestism, en: M. W. Conkey y Ch. A. Hastdorf (eds.), The use of style in archaeology, 32-43. Cambridge University Press, Cambridge.

Shaun, H. (1996). Material culture and cultural identity, en: P. Graves-Brown, S. Jones y C. Gamble (eds.), Cultural identity and archaeology. The Construction of European Communities, 25-47, Routledge, London y New York.

Svendsen, T. (2011). La presencia inca en las pirámides con rampa de Pachacamac: una propuesta para su cronología y función desde la perspectiva de la cerámica, tesis de maestría, Programa de Estudios Andinos, Escuela de Graduados, Pontificia Universidad Católica del Perú, Lima.

Vallejo, F. (2004). El estilo Ychsma: características generales, secuencia y distribución geográfica, Bulletin de l'Institut Françaisd'ÉtudesAndines 33(3), 595-642.

Vallejo, F. (2008). Desarrollo y complejización de las sociedades tardías de la Costa Central: el caso de Ychsma, Arqueología y Sociedad 19, 83-114.

Vallejo, F. (2009). La problemática de la cerámica ychsma: el estado de la situación y algunos elementos de discusión, Revista Chilena de Antropología 20, 133-168.

Van Dijk, T. (2006). Ideología, una aproximación interdisciplinaria, Barcelona, Gedisa.

Fecha de recepción: 5-8-2019

Fecha de aceptación: 16-12-2019 